\title{
Availability and consumption of fruits and vegetables in nine regions of Ethiopia with special emphasis to vitamin A deficiency
}

\author{
Tsegaye Demissie ${ }^{1}$, Ahmed $\mathrm{Ali}^{2}$, Dilnesaw Zerfu ${ }^{1}$
}

\begin{abstract}
Background: Vegetables and fruits are the main sources of a number of essential micronutrients, and therefore, information on availability and consumption of vegetables/fruits is vital in designing sustainable interventions to prevent micronutrient deficiencies, particularly that of vitamin A deficiency.

Objective: The objective of the study was to assess availability and consumption of fruits and vegetables in Ethiopia.

Methods: Employing, multistage cluster sampling approach, a sample of 2552 households in nine administrative regions were interviewed on availability and consumption practice of vegetables and fruits.

Results: In aggregate, $41.5 \%$ and $75.5 \%$ of households did not produce/cultivate any of the common vegetables and fruits over the year preceding the survey, respectively. The proportion of households who did not produce/cultivate vegetables was high in Addis Ababa (99.7\%), Afar (94.9\%), Dire Dawa (94.2\%) and Tigray (86.4\%). The proportion of households who did not produce/cultivate fruits was highest in Addis Ababa (100\%), followed in Dire Dawa (95.3\%), Afar (92.9\%), Tigray (92.2\%), Harari (83.3\%) and Oromiya (81.8\%). In the overall, $38.1 \%$ and $36.5 \%$ of the children studied did not eat vegetable and fruit in the week preceding the survey, respectively. Own production of fruits and vegetables was significantly better $(\mathrm{p}<0.05)$ in rural areas whereas their market availabilities was significantly better $(\mathrm{p}<0.05)$ in urban areas. Analysis of beta carotene contents indicated that kale and carrots contain high amounts $(>4000 \mu \mathrm{g} / 100 \mathrm{gm})$, spinach, mango and papaya contain moderate amounts $(500-800 \mu \mathrm{g} / 100 \mathrm{gm})$, while staple foods contain no or negligible amounts.

Conclusions: Cultivation and consumption of vegetables and fruits is extremely sub-optimal in Ethiopia, calling for strengthened efforts to promote production and consumption of fruits and vegetables. [Ethiop .J. Health Dev. 2009;23(3):216-222]
\end{abstract}

\section{Introduction}

Fruits and vegetables play a number of important roles in human health. They provide antioxidants such as vitamin $\mathrm{A}, \mathrm{C}$ and $\mathrm{E}$ that are important in neutralizing free radicals (oxidants) known to cause cancer, cataracts, heart disease, hypertension, stroke and diabetes $(1,2)$. Fruits and vegetables are the most important sources of vitamin $\mathrm{A}$, a nutrient important for several metabolic activities in the body, in addition to its role as antioxidant. Fruits and vegetables provide foliate and potassium that are known to prevent birth defects, cancer, heart disease, hypertension and stroke. Fruits and vegetables are good sources of minerals such as iron, zinc, calcium, potassium, and phosphorus and contain ample fiber, important for digestion and bowel movements $(1,2,3)$. In the overall, WHO places low fruit and vegetable consumption among its twenty risk factors in global mortality, just behind the better known killers such as tobacco use and high cholesterol levels (4).

Cognizant of these facts, FAO/WHO recommends 400 gram of fruits and vegetables per day or alternatively five servings a day; at least two servings of fruits and three servings of vegetables (5). Moreover, experts recommend consumption of fresh, frozen, dried, or canned fruits and vegetables of a variety of colors and kinds, with more emphasis to dark-green leafy vegetables and orange fruits $(6,7)$.

Agreeably, among several health and nutrition benefits of insuring adequate consumption of fruits and vegetables, prevention of vitamin A deficiency appears to be the most important one, especially in developing countries. Vitamin A deficiency is the major health problem predisposing children to increased risk of morbidity, mortality and disability in developing countries (8).

Several studies in the past and present have established that vitamin A deficiency is a major public health problem in Ethiopia, as elsewhere in developing countries (9-15). Although several factors are known to precipitate vitamin A deficiency, most often in synergy, inadequate consumption of the nutrient appear to outweigh all. Human beings obtain precursors of vitamin A (provitamin A) from plant sources, such as, dark green leafy vegetables, red/yellow vegetables, fruits and preformed vitamin A from animal sources such as liver, organ meat and eggs. Much of the vitamin A (provitamin A), other micronutrients and minerals in developing countries are obtained from plant sources, as livestock sources are inaccessible for most of the rural poor, reflecting the fact that micronutrient status in general and vitamin A status in particular is strongly linked

TEthiopian Health and Nutrition Research Institute, P. O. Box 5654, Tel. 011-2700392; 091-1179804, Fax: 251-112752533, Email: tsegayegemebo@yahoo.com; tsg@ethionet.et, Addis Ababa, Ethiopia; ${ }^{2}$ School of Public Health, Addis Ababa University 
to vegetables/fruits availability and consumption in developing countries. It is estimated that over $80 \%$ of vitamin $\mathrm{A}$ in developing countries is supplied by fruits and vegetables (8)

Thus, it is evident that sustainable improvements in vitamin A status, other micronutrients and minerals require interventions aimed at enhancing availability, access and promotion of consumption of fruits and vegetables. Households must be taught about the importance of consumption of fruits and vegetable in human health and nutrition, particularly in the growth and development of infants and children. Empowerment of communities in terms of awareness creation and technical knowledge must be strongly pursued to enable the cultivation of fruits and vegetables in their backyard gardens.

These endeavors obviously require sound and up-to-date information on the extent of market availabilities, own production/cultivation and consumption of fruits and vegetables. Literature search revealed that such information is unavailable or scanty in Ethiopia. The aim of this study, therefore, is to reinforce the ongoing efforts aimed at promoting production and consumption of fruits and vegetables by availing relevant information to policy makers and implementers. The article is based on the data collected during the national vitamin A deficiency survey conducted in 2006.

\section{Methods \\ Sample Size and Sampling Methods}

The national survey on the magnitude and determinants of vitamin A deficiency conducted between February and June 2006, employed multi-stage cluster sampling approach and cross-sectional study design. As it was intended to report the magnitude of the problem at region level, sample size was determined considering of this intention. Out of the 11 administrative regions, 9 regions were included in the study. Two regions (Gambela and Somali regions) were excluded due to security concerns at the time of the study.

The sample size for the clinical examination in each region was calculated using EPI INFO 2000 (16). Based on the assumptions, $p^{1}=1 \%$, confidence interval $=95 \%$, error margin $= \pm 0.5 \%$ and design effect $=2$, a sample size of about 3000 children was obtained (3000 x 9 regions $=27000$ nationally). It was arbitrarily decided to interview $10 \%$ of the mothers (caretakers) of clinically examined children in each region (300 in each region and 2700 nationally) on availability, production and consumption of fruits and vegetables. Despite unprecedented problems that occurred during the survey, $95 \%$ response rate was attained.

\footnotetext{
${ }^{1} \mathrm{P}$ is the proportion of children with $\mathrm{VAD}$, which was $1 \%$ in the national survey conducted in $1980 / 81$
}

Thirty peasant/urban dwellers associations (the smallest administrative units in Ethiopia) were selected randomly in each region. In each selected peasant/urban dwellers association one study village (cluster) was again selected randomly. The anticipated number of preschool age children in each cluster then was 100 children (3000 divided by 30 clusters) for the clinical examination and 10 mothers/caretakers of children clinically examined for interview. Households were selected systematically and included only those households who have under-six children. When there were more than one under-six children, one child was selected randomly.

Raw and cooked samples of five common vegetables and five common fruits as well as five staple foods were randomly picked in duplicates, from markets for beta carotene analysis. Polyethylene bags were used for the collection and storage of the samples. Food samples were kept in refrigerators until analysis was done. Vitamin A contents (provitamin A) of foods was analyzed in duplicates using HPLC according to Heinonen et al method (17).

\section{Instruments and Data Collection}

Information on own production/cultivation (backyard gardening), market availability and consumption practices of fruits and vegetables were collected through in-depth individual interviews using a structured questionnaire. Households were asked whether they have cultivated/produced any of the common fruits and vegetables in the previous one year. Further more, they were asked that common vegetables and fruits were available in nearby markets in the previous one year and the number of days the index child has consumed the common vegetables and fruits in the preceding week.

Trained data collectors administered the in-depth individual questionnaire. Three days thorough theoretical and practical training was given to the data collectors. Data collection commenced only when common understanding among all data collectors was reached. Pilot survey was conducted in Arsi Zone, Dera woreda and appropriate modifications were made prior to the commencement of the actual survey. In terms of ethical concerns, the purpose of the study was explained in detail to the respondents and their consents were sought. Respondents were interviewed only when they agreed and signed the consent forms.

\section{Data Management}

The data collected through the questionnaires was entered in to SPSS statistical software by experienced data entry clerks. Households who did not produce/cultivate refer to households who did not at all produce/cultivate fruits and vegetables, even not a single seedling over the whole year. Similarly, households who did not see vegetables and fruits in the nearby markets refer to households who never saw a single fruit/ vegetable, even once over the year preceding the survey

Ethiop. J. Health Dev. 2009;23(3) 
in the nearby markets. Moreover, the number of times the index child has consumed fruits and vegetables refers to consuming any amount in the week preceding the survey. Data analysis was done using SPSS statistical software. Frequencies were used to generate proportions. Proportions related to the whole sample, nine regions combined, are weighted proportions.

\section{Results}

The age distribution, illiteracy rate and awareness levels of the mothers included in the study are shown in Table 1. The proportion of the middle age group women $(60.9 \%)$ is higher in all regions, followed by the proportion in younger age category $(27.2 \%)$. The proportion of women who can not read or write was highest in Afar region (89.4\%), followed in Amhara (77.5\%) and BenishangulGumuz (69.8\%) regions. In the overall, 59.2\% could not read and/or write in the nine regions studied. In the aggregate $85.5 \%$ of the studied women in nine regions did not know anything about vitamin A. Over 95.0\% in Afar, 94.4\% in Amhara, 91.5\% in Oromiya, 90.4\% in Addis Ababa, $88.9 \%$ in Benishangul-Gumuz and $85.4 \%$ in Tigray did not know a single aspect of vitamin A.

Table 1: Age, education status and knowledge of mothers included in the study by region, Ethiopia, 2006.

\begin{tabular}{|c|c|c|c|c|c|c|}
\hline \multirow[b]{2}{*}{ Region } & \multirow[b]{2}{*}{$\mathbf{N}$} & \multicolumn{3}{|c|}{ Age } & \multirow[b]{2}{*}{ Can't read/write } & \multirow{2}{*}{$\begin{array}{l}\text { Do not know a } \\
\text { single aspect of VA }\end{array}$} \\
\hline & & $\leq 24$ & $>24-35$ & $>24-35$ & & \\
\hline Afar & 254 & $23.5 \%$ & $89.4 \%$ & $95.2 \%$ & $59.8 \%$ & $59.8 \%$ \\
\hline Tigray & 295 & $31.1 \%$ & $59.7 \%$ & $85.4 \%$ & $54.3 \%$ & $54.3 \%$ \\
\hline Amhara & 267 & $21.5 \%$ & $77.5 \%$ & $94.4 \%$ & $64.5 \%$ & $64.5 \%$ \\
\hline Addis Ababa & 354 & $31.9 \%$ & $28.8 \%$ & $90.4 \%$ & $60.4 \%$ & $60.4 \%$ \\
\hline Oromiya & 236 & $31.5 \%$ & $44.9 \%$ & $91.5 \%$ & $55.7 \%$ & $55.7 \%$ \\
\hline SNNPR* $^{*}$ & 284 & $24.7 \%$ & $64.4 \%$ & $62.2 \%$ & $68.2 \%$ & $68.2 \%$ \\
\hline Benishangul Gumuz & 300 & $35.4 \%$ & $69.8 \%$ & $88.9 \%$ & $55.6 \%$ & $55.6 \%$ \\
\hline Harari & 287 & $34.6 \%$ & $50.2 \%$ & $64.3 \%$ & $58.2 \%$ & $58.2 \%$ \\
\hline Dire Dawa & 275 & $31.0 \%$ & $45.4 \%$ & $71.9 \%$ & $61.2 \%$ & $61.2 \%$ \\
\hline Nine regions & 2552 & $27.2 \%$ & $59.2 \%$ & $85.5 \%$ & $60.9 \%$ & $60.9 \%$ \\
\hline
\end{tabular}

${ }^{*}$ SNNPR $=$ Southern Nations Nationalities and Peoples' Region

The proportion of households who did not produce/cultivate any vegetable was highest in Addis Ababa (99.7\%), followed in Afar (94.9\%), Dire Dawa $(94.2 \%)$, Tigray $(86.4 \%)$ and Harari $(63.1 \%)$ regions (Table 2). In the overall, $41.5 \%$ did not produce any vegetable in nine regions studied. The proportion of households who did not produce any fruit over the year preceding the survey was highest in Addis Ababa (100\%), followed in Dire Dawa (95.3\%), Afar (92.9\%), Tigray $(92.2 \%)$, Harari $(83.3 \%)$ and Oromiya $(81.8 \%)$ regions. The weighted average for the nine regions was $75.5 \%$.

Table 2: Own production/cultivation and market availability situation of vegetables and fruits over the year preceding the survey by region, Ethiopia, 2006.

\begin{tabular}{|c|c|c|c|c|c|}
\hline \multirow[b]{2}{*}{ Region } & \multirow[b]{2}{*}{$\mathbf{N}$} & \multicolumn{2}{|c|}{ Production/cultivation } & \multicolumn{2}{|c|}{ Market availability } \\
\hline & & $\begin{array}{l}\text { Not cultivated any } \\
\text { Vegetable }\end{array}$ & $\begin{array}{l}\text { Not cultivated any } \\
\text { fruit }\end{array}$ & $\begin{array}{l}\text { Not seen any } \\
\text { vegetable }\end{array}$ & $\begin{array}{l}\text { Not seen any } \\
\text { fruits }\end{array}$ \\
\hline Afar & 254 & 94.9 & 92.9 & 82.3 & 79.5 \\
\hline Tigray & 295 & 86.4 & 92.2 & 15.6 & 67.5 \\
\hline Amhara & 267 & 29.2 & 75.3 & 3.4 & 18.0 \\
\hline Addis Ababa & 354 & 99.7 & 100 & 0.8 & 0.8 \\
\hline Oromiya & 236 & 50.0 & 81.8 & 2.1 & 14.8 \\
\hline SNNPR* & 284 & 11.6 & 55.3 & 8.1 & 10.6 \\
\hline Benishangul Gumuz & 300 & 25.3 & 55.0 & 1.7 & 7.3 \\
\hline Harari & 287 & 63.1 & 83.3 & 20.9 & 13.9 \\
\hline Dire Dawa & 275 & 94.2 & 95.3 & 11.3 & 11.3 \\
\hline Nine regions & 2552 & $41.5^{* *}$ & $75.5^{\star *}$ & $15.4^{* *}$ & $24.0^{* *}$ \\
\hline
\end{tabular}

* SNNPR = Southern Nations Nationalities and Peoples' Region; ** nine regions proportions are weighted proportions

Awareness about availability of common vegetables in nearby markets over the year preceding the survey indicated that high proportion of households in Afar $(82.3 \%)$ did not see any of the vegetables mentioned in the nearby markets (Table 2). Most households in Afar $(79.5 \%)$ and in Tigray $(67.5 \%)$ reported that they have not seen any fruit in the near by markets over the year preceding the survey.
Overall, among all the index children studied in nine regions, $38.1 \%$ did not eat any of the common vegetables (kale, spinach, cabbage, carrot, tomato and pumpkin) over the week preceding the survey (Table 3 ). The proportion of index children who did not eat any vegetable was high in Afar (85.0\%), Tigray (77.6\%), Amhara (61.8\%) and Addis Ababa (59.3\%) and relatively 
low in SNNPR $^{2}(7.0 \%)$, Dire Dawa (15.6\%) and Oromiya (18.6\%). Among all the children studied in nine regions, $36.5 \%$ did not eat any of the common fruits (mango, papaya, oranges, avocado and banana) over the week preceding the survey. The proportion of index children who did not eat fruits was high in Tigray $(88.1 \%)$ and Afar (83.5\%) and was relatively low in Harari. $(23.3 \%)$.

\footnotetext{
${ }^{2}$ Southern Nations Nationalities and Peoples' Region
} 

Table 3: Proportion of children who did not eat any of the common vegetables and fruits over the week preceding the survey by region, Ethiopia, 2006.

\begin{tabular}{llll}
\hline Region & N & Vegetables & Fruits \\
\hline Afar & 254 & 85.0 & 83.5 \\
Tigray & 295 & 77.6 & 88.1 \\
Amhara & 267 & 61.8 & 30.3 \\
Addis Ababa & 354 & 59.3 & 33.9 \\
Oromiya & 236 & 18.6 & 28.0 \\
SNNPR* & 284 & 7.0 & 35.2 \\
Benishangul Gumuz & 300 & 38.3 & 41.3 \\
Harari & 287 & 35.5 & 23.3 \\
Dire Dawa & 275 & 15.6 & 31.6 \\
Nine regions & 2552 & $38.1 \%{ }^{*}$ & $36.5^{*}$ \\
\hline
\end{tabular}

* SNNPR = Southern Nations Nationalities and Peoples' Region

** nine regions proportions are weighted proportions

Comparative analysis of the situation regarding production, market availability and consumption of fruits and vegetables between predominantly urban areas (Dire Dawa, Addis Ababa and Harari) and predominantly rural areas (Amhara, SNNPR, Benishangul-Gumuz, Tigray, Oromiya and Afar) showed that significantly more rural households have produced/cultivated vegetables and fruits $(\mathrm{P}<0.001)$ compared to urban households (Table 4). In the contrary significantly more urban households $(\mathrm{P}<0.001)$ have reported that vegetable and fruits were available in the markets compared to rural households. The proportion of index children who consumed vegetables in a week prior to the survey was not different between the groups. However, the proportion of the index children who have consumed fruits was significantly higher among the urban dwellers $(\mathrm{P}<0.001)$ compared to the rural dwellers.

The result of the beta carotene analysis of common vegetables, fruits and staple foods consumed in Ethiopia is depicted in Table 5. Uncooked kale and raw carrots contain the highest amounts (5800-6100 $\mu \mathrm{g} / 100 \mathrm{gm})$ of beta-carotene, spinach, mango and papaya were found to contain relatively high amounts (500-800 $\mu \mathrm{g} / 100 \mathrm{gm})$, tomatoes and pumpkin contain modest amounts (about $200 \mu \mathrm{g} / 100 \mathrm{gm})$, while cabbage, orange, banana, potato, and staple foods contain no or little amount (nil to 50 $\mu \mathrm{g} / 100 \mathrm{gm})$ beta-carotene.

Table 4: Production, availability and consumption of common vegetables and fruits by residence, 2006, Ethiopia

\begin{tabular}{|c|c|c|c|c|}
\hline Attribute & Response & $\begin{array}{l}\text { Predominantly } \\
\text { urban }(n=916) \\
\%\end{array}$ & $\begin{array}{l}\text { Predominantly } \\
\text { rural }(n=1630) \\
\%\end{array}$ & Significance* $^{*}$ \\
\hline \multirow[t]{2}{*}{ Vegetable production } & No & 86.6 & 49.1 & $P<0.001$ \\
\hline & Yes & 13.4 & 50.9 & \\
\hline \multirow[t]{2}{*}{ Fruit production } & No & 93.3 & 75.1 & $P<0.001$ \\
\hline & Yes & 6.7 & 24.9 & \\
\hline \multirow[t]{2}{*}{ Vegetable availability } & No & 10.3 & 18.2 & $P<0.001$ \\
\hline & Yes & 89.7 & 81.8 & \\
\hline \multirow[t]{2}{*}{ Fruit availability } & No & 8.1 & 33.0 & $P<0.001$ \\
\hline & Yes & 91.9 & 67.0 & \\
\hline \multirow[t]{2}{*}{ Vegetable consumption } & No & 39.0 & 38.0 & NS \\
\hline & Yes & 61.0 & 62.0 & \\
\hline \multirow[t]{2}{*}{ Fruit consumption } & No & 30.0 & 40.1 & $P<0.001$ \\
\hline & Yes & 70.0 & 59.9 & \\
\hline
\end{tabular}

*based on chi square statistic NS=Not Significant

Table 5: $\beta$ Carotene contents of the common vegetables, fruits and some staple foods consumed in Ethiopia, 2006.

\begin{tabular}{|c|c|c|c|c|c|}
\hline \multicolumn{3}{|c|}{ Vegetables and fruits } & \multicolumn{3}{|c|}{ Staple foods } \\
\hline Type & $\mu \mathrm{g} / 100 \mathrm{gm}$ & $\begin{array}{l}\text { EFCT }^{*} \quad \text { values } \\
(\mu \mathrm{g} / 100 \mathrm{gm})\end{array}$ & Type & $\mu \mathrm{g} / 100 \mathrm{gm})$ & $\begin{array}{l}\text { EFCT }^{*} \text { values } \\
(\mu \mathrm{g} / 100 \mathrm{gm})\end{array}$ \\
\hline
\end{tabular}

${ }^{T}$ Ethiopian Health and Nutrition Research Institute, P. O. Box 5654, Tel. 011-2700392; 091-1179804, Fax: 251-112752533, Email: tsegayegemebo@yahoo.com; tsg@ethionet.et, Addis Ababa, Ethiopia; ${ }^{2}$ School of Public Health, Addis Ababa University 


\begin{tabular}{llllll}
\hline Kale (raw) & 6100.45 & 2330 & Injera & B.D.L. & B.D.L \\
Kale (cooked) & 4400.08 & 11.25 & Teff flour & B.D.L & B.D.L \\
Carrot (raw) & 5800.09 & 4780 & Shiro wot & 600.21 & 684 \\
Carrot (cooked) & 4300.30 & 1.15 & Shiro flour & 100.60 & Trace \\
Spinach (Raw) & 800.12 & 3.06 & Wheat flour & 27.17 & 0.16 \\
Spinach & 500.18 & 2.19 & Bread & 5.98 & 0.09 \\
(cooked) & & & & & \\
Cabbage (raw) & 46.97 & 0.09 & Potato (raw) & 4.67 & B.D.L \\
bbage(cooked) & 12.47 & 0.04 & Potato (boiled) & B.D.L & B.D.L \\
Orange & 65.69 & 0.8 & Kocho (Raw) & B.D.L & B.D.L \\
Banana & 58.72 & B.D.L & Kocho (Baked) & B.D.L & B.D.L \\
Mango & 500.54 & B.D.L & & & \\
Avocado & B.D.L & B.D.L & & & \\
Pawpaw & 800.86 & 0.04 & & & \\
Tomato (raw) & 200.29 & 620 & & & \\
Pumpkin (raw) & 200.63 & 280 & & & \\
\hline
\end{tabular}

EFCT $^{*}$ = Ethiopian Food Composition Tables; B.D. $L^{*}=$ Below Detectable Levels; Trace1 = some beta carotene activity

\section{Discussion}

Although factors such as malnutrition, illnesses and unavailability of fat in the diet, contribute towards vitamin A deficiency $(18,19)$, inadequate intake of foods containing vitamin A appears to constitute the single most important risk factor to VAD in developing countries (8). Inadequate intake of foods containing vitamin A is basically due to lack of access to vitamin A rich foods, which is a function of inadequate production, inadequate availability in the market or inability to purchase the foods.

With regards to the practice of own production/cultivation of common vegetables and fruits, the study showed a bleak picture in Ethiopia. When the fact that the proportion of households who reported to have cultivated/produced included those who had a single seedling/plant of a vegetable/fruit in their gardens even once over the year is considered, it is obvious that the proportion of households who produced adequate fruits and vegetables in their gardens/homesteads is negligible. Based on WHO recommendations suggesting unavailability of dark green leafy vegetables for more than six months in an area as indicative of increased risk to VAD (20), many regions in Ethiopia can be considered as VAD endemic. The situation in Afar, Addis Ababa, Harari, Tigray and Dire Dawa exhibits worst scenarios. Simultaneously, conducted survey on the magnitude and distribution of subclinical vitamin A deficiency indicated that the prevalence was high in these regions, suggesting a potential negative contribution of poor backyard gardening practice to vitamin A deficiency (21).

Much of the soil and climate in many parts of the country is favorable for horticulture, as evidenced by a number of ongoing investments in the sector. Lessons learned from successful urban agricultural projects in many parts of the world $(22,23)$, indicated that even urban households can produce adequate vegetables for household consumption. Apparently, the major impediment to own production in Ethiopia appears to be lack of awareness about the importance of fruits and vegetables in the wellbeing of children and women.

Overall, market availability of fruits and vegetables appear to be relatively good compared to own production, but there are gaps in some regions that might need interventions. For example, market availability of fruits and vegetables is worrisome in Afar and Tigray regions and deserve attention.

The findings regarding consumption of vegetables and fruits indicated that the practice is sub-optimal in Ethiopia. Majority of the children did not at all eat vegetable and fruit over the week preceding the survey and when the proportion of children who have eaten once or twice (inadequate consumption) is also considered, it is apparent that vegetable and fruit consumption is indeed extremely suboptimal in Ethiopia. WHO suggests that if less than $75 \%$ of preschool age children consume vitamin A rich foods at least three times a week (17), the community/population should be considered as at risk community/population. Based on this suggestion, many communities in Ethiopia can be considered as 'at risk community'. The proportion of children who did not eat vegetables even once, let alone three times in a week is greater than $75 \%$ in Afar and Tigray regions. FAO estimates that Ethiopians eat less than 100 gram of fruits and vegetables/per day, a size of a medium carrot, which is less than a quarter of the recommended fruit and vegetable consumption $(5,24)$.

Although this study and other studies did not explore why vegetables and fruits are not widely consumed in Ethiopia, a few likely reasons can be forwarded based on the dietary habits in the country. In most parts of the country, the diets are monotonous, consisting of a cereal and legume, cereal or milk and roots/tubers with legumes/diary products. For example, injera (thin bread made up of flour of a cereal known as 'teff') and wot (sauce of lentils, pea, beans) is the monotonous diet in the north and in towns, while sorghum/maize/wheat bread or porridge and milk are the common foods in the 
lowlands. Moreover, there is wrong perception by most of the population that the monotonous diet is adequate and superior to vegetables. The results of the analysis of vitamin A content of foods, however, clearly indicated that vitamin A content of teff and injera, wheat bread and 'kocho' is close to nil. While the content in shiro wot is relatively better vis-à-vis other staple foods, it is insignificant compared to beta carotene content in some vegetables and fruits. The relatively high levels of beta carotene in shiro wot compared to the shiro flour (flour of pea) appears to be due to the ingredients added to the sauce such as pepper and tomatoes.

Comparisons of the beta carotene contents of common vegetables, fruits and staple foods obtained in this study and beta carotene contents reported in the Ethiopian Food Composition Tables showed some variations. The values in the Composition Table appear to be considerably underestimated. This is anticipated because analytical procedures were different. The analysis that generated the values in Food Composition Table used open column chromatography for extraction and spectrophotometer for quantification, while HPLC was used for both extraction and quantification in this study. This finding suggests that revising the food composition tables using the more sensitive HPLC methods might be needed.

Comparisons of own production, market availability and consumption practice of fruits and vegetables between predominantly urban community and predominantly rural community yielded expected results. The situation regarding homestead gardening is relatively better among rural population, while market availability of both fruits and vegetables as well as consumption of fruits were better in urban areas. This calls for strengthened efforts to promote urban agriculture in towns and to strengthen efforts to enhance availability and consumption of fruits and vegetables in rural areas.

As reiterated elsewhere, the study was limited in some aspects. One of the limitations of the study is related to lack of data on the actual quantities of the vegetables and fruits produced by the households and consumed by the children. In surveys as big as this one, constrained by human resource, budget and time, collecting data on quantities proved difficult. As a result of lack of information on actual quantities, examination of the association of household's production, availability and consumption of fruits and vegetables with vitamin A status of children could not be done.

\section{Acknowledgements}

The study was funded by UNICEF and the implementation of the survey was facilitated by Federal Ministry of Health and Ethiopian Health and Nutrition Research Institute. We thank the organizations.

\section{References}

1. Quebedeaux B, Bliss F. Horticulture and human health: contributions of fruits and vegetables. Proc. $1^{\text {st }}$ Intl. Symp. 1988. Hort. and Human Health Prentice.

2. Wargovich M. Anticancer properties of fruits and vegetables. Hort Science. 2000. 35:573-575.

3. Prior R, Cao G. Antioxidant photo-chemicals in fruits and vegetables; diet and health implications. Hort Science. 2000. 35:588-592.

4. The International Bank for Reconstruction and Development/World Bank. Burden of Disease/Comparative Risk Assessment. 2006. Washington DC 20433.

5. World Health Organization. Diet, nutrition and the prevention of chronic diseases. Report of a joint WHO/FAO expert consultation. WHO Geneva; 2003.

6. USDA. Nutrition and your health: dietary guidelines for Americans. Home and Garden Bull. 2000. U.S. Dept. Agri., Washington, D.C.

7. Deckelbaum R. Summary of a scientific conference on preventive nutrition: pediatrics to geriatrics. Circulation, 1999. 100(4):450-456.

8. Mclaren D, Frigg M. Sight and Life Manual on vitamin A deficiency disorders. Second edition. Task Force Sight and life, Switzerland. 2001.

9. Postumus S. Report on Nutritional needs of children in Ethiopia. 1958. FAO Report. Rome, Italy.

10. Interdepartmental committee on Nutrition for National Defense. Ethiopia Nutrition Survey. 1959. Washington DC. US Government Printing Office, publication - 598935.

11. De Sole G, Belay Y. Zegeye B. Vitamin A deficiency in Southern Ethiopia. AM. J. Clin Nutr. 1987. 45: 780784.

12. Wolde-Gebriel $Z$, Demeke $T$ and West CE. Xerophthalmia in Ethiopia: a nationwide ophthalmologic, biochemical and anthropometric survey. European J. Clin. Nutri. 1991. 45:469-478.

13. Demisse T, Haidar J, Gebre Selassie H, Birratu E, Fuffa H. Vitamin A status in three woredas of Kembatta, Alaba and Timbarro zone, SNNRP region. Ethiop J Health Dev. 1998. 12(3):225-229.

14. Demissie T, Haider J, Neka Tibeb H and H/Giorgis B. Impact evaluation of WIBS and EPI-plus approaches in controlling Vitamin A deficiency in Tigray and Harari regions, Ethiopia. Ethiop J Health Dev. 2000. 14(3):303-310.

15. ACC/SCN. $5^{\text {th }}$ report on the world nutrition situation. 2004. United Nations Geneva.

16. EPI INFO. 2000. Version 3.2.2.

17. Heinonen M. Carotenoids in Finnish foods, vegetables, fruits and berries. Agric Food Chem. 1989. 37:655-659.

18. Beateon G, Martorell R, Aronson K. Effectiveness of vitamin A supplementation in the control of young child morbidity and mortality in developing countries. 1993. ACC/SCN state of the art series nutrition policy discussion paper no.13. United Nations Geneva.

19. West K, Katz J, Khatry S. Double blind cluster Randomized trail of low dose supplementation with

Ethiop. J. Health Dev. 2009;23(3) 
vitamin a or beta-carotene on mortality related to pregnancy in Nepal. British Medical Journal. 1999. 318: 570-575.
20. WHO. Indicators for assessing Vitamin A deficiency and their application in monitoring and evaluating intervention programs. 1996. WHO, Geneva.

21. Demissie T, Ali A, Mekonnen Y, Haider J, Umeta M. Demographic and health related risk Factors of subclincal vitamin A deficiency in Ethiopia. J. Pop. Health and Nutri. In press.

22. Jianmins C. Peri-urban agriculture development in China. Urban agriculture magazine. 2003. 9: 54-65.

23. Fraser D and Evan G. Urban Ecology in Bangkok Thailand: Community Participation, Urban Agriculture and Forestry. Environment. 2002. 30(1) 35-45.

24. FAO/WHO. Report of a Joint FAO/WHO fruit and vegetable for health workshop, 1-3 September, 2004, Kobe, Japan. 